\title{
Diagnóstico e Análise de Sistemas da Qualidade: Um Modelo para Avaliação e Preparação dos Sistemas para a Certificação ISO 9000
}

\author{
Denise Dumke de Medeiros, Docteur \\ Professora - Universidade Federal de Pernambuco \\ Programa de Pós-Graduação em Engenharia de Produção \\ Av. Acadêmico Hélio Ramos s/n - 50.740-530 - Recife - PE \\ e-mail:ddm@npd.ufpe.br
}

\begin{abstract}
Resumo
Este artigo apresenta um modelo baseado em três elementos fundamentais de um sistema da qualidade: a responsabilidade da Administração, os recursos humanos e materiais, e a estrutura do próprio sistema. Estes fatores possibilitam um diagnóstico objetivo dos elementos que compōem um sistema da qualidade. Săo apresentados os resultados obtidos numa pesquisa de campo em aproximadamente uma centena de empresas. Os dados obtidos resultaram numa tipologia de 5 grupos de empresas, segundo a maneira de organizar seus sistemas da qualidade. O modelo para o diagnóstico dos sistemas da qualidade se mostra uma ferramenta adequada principalmente em duas situaçóes: para as empresas que querem iniciar um programa da qualidade total e para as empresas que desejam iniciar seus projetos de certificação à uma das normas ISO 9000 , pois permite a visualização dos pontos fortes e fracos da organização com relaçāo à qualidade para as empresas do primeiro caso, e considera aspectos fundamentais dos sistemas da garantia da qualidade para as outras.
\end{abstract}

Abstract

This work presents a model based on three fundamental elements of a quality system: the responsibility of the Administration, the human resources and materials, and the structure of the system itself. These elements allow an objective diagnosis of the elements that compose a quality system. Results obtained in a research in approximately a hundred of companies are presented. The obtained results resulted in a typology of 5 groups of companies, according to the way to organize their quality systems. The model for the diagnosis of quality systems is shown very useful to companies in two main situations: companies that wish to begin a program of total quality, and companies that want to begin their certification projects to one of the ISO 9000 standards. Because the proposed model allows the visualization of strong and weak points of the existing organization concerning the quality, for the companies in the first case. And it considers fundamental aspects of quality system assurance to others companies.

Palavras Chaves:

Sistemas da Qualidade, Estrutura de Sistemas, Diagnóstico de Sistemas da Qualidade

Keyword:

Quality Systems, Structure of Systems, Diagnostic of Quality Systems

\section{Introdução}

Sabe-se que há uma perfeita adequação conceitual entre Qualidade e Sistema, pois em termos de organização interna, as empresas necessitam de estruturas organizadas para produzir e manter a Qualidade. A norma ISO 8402 conceitua os Sistemas da Qualidade consi derando a estrutura organizacional, os procedi- mentos, os processos e os recursos necessários à implementação da gestão da qualidade. O modelo apresentado neste trabalho para a realização de diagnóstico e análise dos Sistemas da Qualidade das empresas é baseado em três fatores-chaves que devem compor este tipo de sistema: a responsabilidade da Administração, os recursos humanos e materiais e a estrutura do próprio sistema. 
PRODUÇÃO

Estes três fatores-chaves podem ser considerados como o conjunto de ações fundamentais do esforço pela qualidade. Assim, a harmonia entre eles é uma das condições necessárias para a gestão da qualidade nas empresas e consequentemente para satisfazer os clientes.

Um estudo realizado em 96 empresas, com aplicação de questionário e análise estatística dos dados, resultou em uma tipologia de sistemas da qualidade caracterizados segundo os elementos que compõem os três fatores-chaves citados acima.

2 . Modelo proposto para diagnóstico dos sistemas da qualidade

A principal finalidade de um sistema da qualidade é satisfazer os clientes e utilizadores dos produtos e serviços da empresa. Vários autores como Defourny e Noyé (1996), definem este tipo de sistema baseados na norma ISO 8402 (1994): "estrutura organizacional, procedimentos, processos e recursos necessários para implementar a gestão da qualidade".

A necessidade de sistemas da qualidade nas empresas é amparada pela necessidade de haver uma organização formal para a implementação e manutenção da gestão da qualidade. Se o sistema da qualidade estrutura a organização necessária para a implementação da gestão da qualidade, é porque ele deve estar presente em todas as fases do ciclo de vida dos produtos e dos processos desde a identificação inicial das necessidades do mercado até a satisfação das exigências dos clientes. As fases do ciclo de vida de um produto envolvidas com o sistema da qualidade, segundo a norma ISO 9004-1 (1994), são as seguintes: marketing e pesquisa de mercado, projeto e desenvolvimento de produto, planejamento e desenvolvimento de processo, aquisição, produção ou fornecimento de serviços, verificação, embalagem e armazenamento, vendas e distribuição, instalação e comissionamento, assistência técnica e serviços associados, pós-venda e reciclagem ou disposição após o uso.

No modelo proposto neste trabalho, foram considerados os elementos básicos que devem compor um sistema e como estes elementos atuam em todas as fases do ciclo de vida. Esta análise resultou em um modelo composto por três fatores-chaves:

- a responsabilidade da Administração,

- os recursos humanos e materiais,

- e a estrutura do sistema da qualidade.

A convergência destes três fatores é a satisfação do cliente. Estes fatores devem representar os aspectos necessários ao bom funcionamento da Qualidade nas empresas. Assim, a harmonia entre suas interações é uma das condições para a satisfação dos clientes.

O modelo proposto neste trabalho para análise do sistema da qualidade torna possível o diagnóstico dos mesmos nas empresas. Tem-se assim, um método para auxiliar as empresas que estão no processo de implementação de um sistema de garantia de qualidade baseado em uma das normas da série ISO 9000, a visualizarem os pontos fortes e fracos do sistema vigente. Isto pode possibilitar um processo mais adaptado à realidade da empresa, no momento de implementação dos requisitos da norma.

O modelo pode servir também como uma ferramenta para auxiliar na correção das disfunções e na melhoria contínua de todos os elementos que compõem um Sistema da Qualidade.

Nos parágrafos seguintes, é apresentada uma descrição de cada fator-chave do sistema da qualidade. 


\section{1 . Responsabilidade da administração}

Num sistema da qualidade, este primeiro fator-chave diz respeito à elaboração, aplicação e divulgação da política da qualidade e dos objetivos que a empresa tem com relação à qualidade. Para o bom funcionamento do sistema, é necessário que a Administração defina claramente e reveja periodicamente a responsabilidade e a autoridade relativa à qualidade de cada participante do processo.

Para a implantação de um Sistema da Qualidade e obtenção dos objetivos da qualidade que foram estabelecidos, a Administração deve colocar à disposição dos responsáveis, os recursos necessários e suficientes em pessoal e em material (Juran, 1993).

\subsection{Recursos humanos e materiais}

Para o bom desenvolvimento de um sistema da qualidade, a direção deve promover programas para motivar e qualificar o pessoal ao trabalho com a qualidade. Segundo a norma ISO 9004-2 (1991), cabe à direção da empresa a atividade de estabelecer programas para recrutar o pessoal; fornecer as condições de trabalho adequadas; tornar possível a participação de todos; assegurar que todos compreendam as tarefas que eles têm a realizar, sua importância e a influência destas tarefas sobre a qualidade; reconhecer e valorizar as ações que podem trazer melhorias para a qualidade; efetuar periodicamente uma avaliação dos principais fatores que podem incitar o pessoal a trabalhar pela qualidade; e promover a formação do pessoal a todos os níveis.

Para assegurar a aptidão dos empregados a trabalhar pela qualidade, a empresa deve determinar os níveis necessários de experiência, de competência e de formação do pessoal. Outro compo- nente deste fator-chave são os recursos materiais. Os recursos materiais necessários para a implementação e funcionamento do sistema da qualidade devem ser identificados e fornecidos (Deming, 1990). Os principais recursos materiais utilizados nos sistemas da qualidade são: equipamentos e instalações para a produção; sistema de informação; equipamentos, softwares e instrumentos necessários para a avaliação da qualidade; documentação das áreas operacional e técnica, entre outros.

\subsection{Estrutura do sistema da qualidade}

A organização do sistema da qualidade é um dos meios pelos quais a empresa pode tornar possível a obtenção dos objetivos da qualidade e o respeito às políticas da qualidade. Cabe à direção da empresa desenvolver, estabelecer e colocar em funcionamento o sistema da qualidade, como também de mantê-lo e melhorá-lo.

Para a norma ISO 9004-1 (1994), a estrutura do sistema da qualidade das empresas deve enfatizar cinco elementos: a responsabilidade e a autoridade; a organização; os procedimentos operacionais; os recursos e o pessoal; e a gestão de configuração.

Segundo a norma ISO 9004-2 (1994), os sistemas da qualidade para as empresas prestadoras de serviços devem ter seus elementos estruturados de maneira a estabelecer o controle e a garantia da qualidade, no que se refere aos processos operacionais que podem afetar a qualidade. Para os outros tipos de empresas, os sistemas da qualidade também devem possuir uma estrutura que enfatize principalmente três elementos: ciclo da qualidade do serviço; a documentação e os registros da qualidade; e as auditorias internas da qualidade. 
PRODUÇÃO

Para avaliar a estrutura dos sistemas da qualidade no modelo proposto neste trabalho, foram adotados cinco elementos: a organização; o manual da qualidade; os procedimentos operacionais; os registros da qualidade; e as auditorias internas da qualidade.

\section{Metodologia adotada na aplicação do modelo}

Para validar o modelo proposto para o diagnóstico dos sistemas da qualidade baseado nos três fatores-chaves, foi realizada em 1997, uma pesquisa de campo que teve como população 96 empresas que haviam passado pelo processo de certificação ISO 9002 (De Medeiros, 1998). Os sistemas da qualidade destas empresas foram avaliados de acordo com os aspectos que os mesmos apresentavam antes de iniciar a implementação da referida norma. Foram analisadas variáveis relacionadas aos três fatores-chaves que devem compor este tipo de sistema: a responsabilidade da Administração, os recursos humanos e materiais e a estrutura do próprio sistema.

\subsection{Coleta dos dados}

Para a coleta de dados, foi elaborado um questionário, dado que a população era de tamanho considerável e havia um grande número de dados a recolher (Richardson, 1985). Foram realizadas seis etapas para elaborar o questionário, sendo definidos sucessivamente: os dados a recolher; a modalidade da pesquisa; o conteúdo e o tipo de questão a adotar; o tipo de análise estatística a adotar nas questões; o pré-teste; e a redação da versão final do questionário.

Na versão final do questionário, foram previstas treze variáveis para avaliar diretamente os três fatores-chaves do sistema da qualidade e outras seis variáveis para avaliar o grau de formalismo dos sistemas da qualidade. Para cada fator-chave, as variáveis adotadas são apresentadas abaixo:

Responsabilidade da Administração: v1 - estado da política da qualidade, v2 - adequação da política da qualidade, v3 - estado dos objetivos da qualidade, v4 - realização dos objetivos da qualidade.

Recursos humanos e materiais:

v5 - maneira de se preocupar com a qualidade, v6 - realização de um programa de formação do pessoal à qualidade,

v7 - compatibilidade do material com a política da qualidade.

\section{Estrutura do sistema da qualidade:}

v8 - definição das funções, relações hierárquicas e dos circuitos de comunicação, v9 - definição do Manual da Qualidade, v10 - verificação do Manual da Qualidade, v11 - definição dos documentos relacionados com a qualidade,

v12 - verificação dos documentos relacionados com a qualidade,

v13 - realização de auditorias internas da qualidade.

O grau de formalismo dos sistemas da qualidade foi avaliado no questionário através de seis variáveis. Estas variáveis correspondem aos principais documentos do sistema da qualidade $\mathrm{e}$ são apresentadas abaixo:

v14 - definição da política da qualidade, v15 - verificação da política da qualidade, v16 - definição dos objetivos da qualidade, v17 - verificação da realização dos objetivos da qualidade,

v18 - definição de programas para a formação do pessoal à qualidade,

v19 - definição das funções, relações hierárquicas e dos circuitos de comunicação. 
Para avaliar os componentes das treze variáveis que caracterizam os três fatores-chaves do sistema da qualidade, foram utilizadas no questionário, questões com resposta em escala entre 0 e 5 , onde 0 representa a ausência deste elemento e 5 representa a presença quotidiana do elemento no sistema da qualidade.

Um exemplo de questão adotada para avaliar a variável v13 (realização de auditorias internas da qualidade), é apresentada na Figura 1 abaixo: veis marcam a importância da 'responsabilidade da Administração ' na qualidade. O segundo componente é explicado por cinco variáveis do fator-chave 'estrutura do sistema da qualidade': v9, v10, v11, v12 e v13. O terceiro componente da ACP é explicado pelas variáveis relacionadas com a participação dos 'recursos humanos' no sistema da qualidade: as variáveis v5 e v6. E o quarto componente é explicado pela variável v7, relacionada com os 'recursos materiais'.

\begin{tabular}{|lc|}
\hline A auditoria interna da qualidade na empresa é: & valor na escala \\
[ ] jamais realizada & 0 \\
[ ] muito raramente realizada & 1 \\
[ ] realizada poucas vezes & 2 \\
[ ] realizada de tempos em tempos & 3 \\
[ ] realizada de maneira quase regular & 4 \\
[ ] realizada sempre periodicamente & 5 \\
\hline
\end{tabular}

Figura 1 - Exemplo de questão

\subsection{Análise dos dados coletados}

Para a análise estatística dos dados, foi utilizado o software estatístico SPSS. Foram realizados com as treze variáveis que representam os três fatores-chaves, os seguintes procedimentos: Análise em Componentes Principais (ACP), seguida de Análise Fatorial e concluída pela Análise Discriminante.

Na realização da ACP utilizando o procedimento 'Factor' do programa SPSS, quatro componentes explicam juntos $72,5 \%$ da variância total: $41,65 \%$ para o primeiro componente, $13,26 \%$ para o segundo componente, $9,41 \%$ para o terceiro componente e $8,18 \%$ para o quarto componente.

O primeiro componente é explicado por cinco variáveis: v1, v2, v3, v4 e v8. Estas variá-
Com estes quatro componentes resultantes da ACP, foi realizada uma análise fatorial não hierárquica através da utilização do procedimento 'K-Means Cluster Analysis' do programa SPSS. Para escolher qual tipologia utilizar, foi adotado o critério da quantidade de informação restituída pelos grupos, representada pelo indicador da relação entre a variância intergrupo e a variância total em cada tipologia. A tipologia em cinco grupos foi a escolhida por apresentar o melhor indicador desta relação.

A análise fatorial foi construída a partir de 91 observações, formando cinco grupos de empresas segundo a situação do sistema da qualidade, pois da população de 96 empresas, cinco questionários não foram preenchidos corretamente e tiveram que ser abandonados. Os grupos foram formados da seguinte maneira: 
PRODUÇÃO

grupo 1: 16 empresas,

-grupo 2: 14 empresas,

grupo 3: 26 empresas,

-grupo 4: 18 empresas,

-grupo 5: 17 empresas.

A partir desta tipologia, foi realizada uma análise discriminante utilizando-se o procedimento 'Discriminant' do programa SPSS. Esta tipo de análise permite uma melhor separação entre os cinco grupos, através da utilização das 13 variáveis iniciais que avaliam diretamente os três fatores-chaves para diagnosticar os sistemas da qualidade. $O$ resultado indicou que $86,8 \%$ das empresas foram bem classificadas. A análise discriminante permite uma representação gráfica que mostra a separação entre os grupos e que é apresentada na Figura 2 abaixo.
As sete variáveis que se mostraram discriminantes na análise estatística para explicar as diferenças entre os grupos são as variáveis v4, v5, v6, v7, v8, v10 e v12.

A primeira função se mostrou fortemente correlacionada com as variáveis $\mathrm{v} 8, \mathrm{v} 10 \mathrm{e} \mathrm{v12}$, que representam o fator-chave 'estrutura do sistema da qualidade'. A segunda função é fortemente correlacionada com as variáveis $\mathrm{v} 4$, v5, v6 e v7, onde a primeira variável é ligada ao fator-chave 'responsabilidade da Administração' e as três outras estão relacionadas ao fator-chave 'recursos humanos e materiais'.

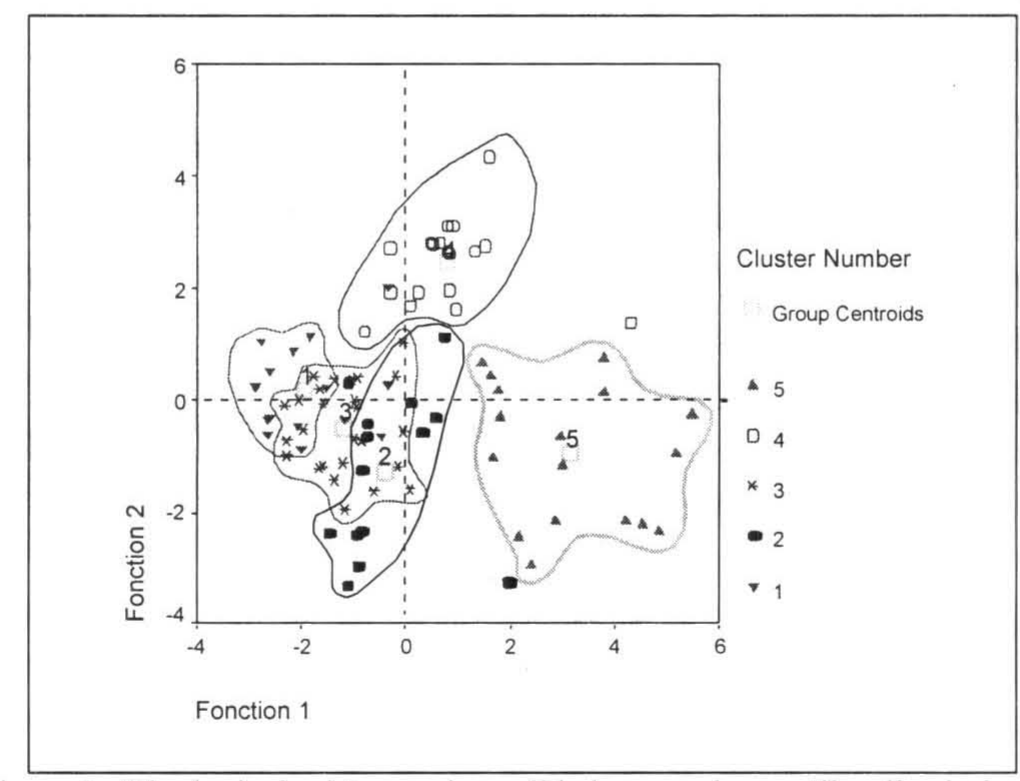

Figura 2 - Tipologia de sistemas da qualidade segundo a análise discriminante

A análise discriminante resultou em quatro funções que explicam a variância total da análise. Considerou-se somente as duas primeiras, pois elas explicam 73,2 \% da variância, o que foi julgado suficiente para compor a diferença entre os grupos.
4. Resultados obtidos na validação do modelo

Com a análise estatística apresentada, foram formados cinco grupos distintos de empresas com relação aos três fatores-chaves. Esta formação 
está relacionada com as diferenças em sete das treze variáveis previstas no modelo de diagnóstico e análise dos sistemas da qualidade. São apresentadas na tabela I a seguir, estas sete variáveis discriminantes e o comportamento das empresas de cada grupo com relação a elas.
Pode-se verificar pelos dados acima, que os cinco grupos apresentam desempenhos diferentes com relação às variáveis apresentadas. Os cinco grupos foram dispostos na tabela da seguinte maneira: o grupo de empresas onde o sistema é mais organizado é o que está no extremo do lado direito.

\begin{tabular}{|c|c|c|c|c|c|}
\hline \multirow[t]{2}{*}{ Variáveis } & \multicolumn{5}{|c|}{ Comportamento nos Grupos (e efetivo de empresas) } \\
\hline & Grupo $1(16)$ & Grupo 2 (14) & Grupo $3(26)$ & Grupo 4 (18) & Grupo $5(17)$ \\
\hline $\begin{array}{l}\text { v4 } \\
\text { realização dos } \\
\text { objetivos da } \\
\text { qualidade }\end{array}$ & jamais verificado & $\begin{array}{l}\text { verificado } \\
\text { poucas vezes }\end{array}$ & jamais verificado & $\begin{array}{l}\text { verificado } \\
\text { regularmente }\end{array}$ & $\begin{array}{l}\text { Verificado de } \\
\text { tempos em } \\
\text { tempos }\end{array}$ \\
\hline $\begin{array}{l}\text { v5 } \\
\text { maneira do } \\
\text { pessoal de se } \\
\text { preocupar com a } \\
\text { qualidade }\end{array}$ & $\begin{array}{l}\text { regularmente } \\
\text { preocupado }\end{array}$ & $\begin{array}{l}\text { muito pouco } \\
\text { preocupado }\end{array}$ & $\begin{array}{l}\text { preocupado de } \\
\text { tempos em } \\
\text { tempos }\end{array}$ & $\begin{array}{l}\text { preocupado de } \\
\text { tempos em } \\
\text { tempos }\end{array}$ & $\begin{array}{l}\text { Preocupado de } \\
\text { tempos em } \\
\text { tempos }\end{array}$ \\
\hline $\begin{array}{l}\text { v6 } \\
\text { realização de um } \\
\text { programa de } \\
\text { formação do } \\
\text { pessoal à } \\
\text { qualidade }\end{array}$ & $\begin{array}{l}\text { realizado poucas } \\
\text { vezes }\end{array}$ & $\begin{array}{l}\text { muito raramente } \\
\text { realizado }\end{array}$ & $\begin{array}{l}\text { muito raramente } \\
\text { realizado }\end{array}$ & $\begin{array}{l}\text { realizado de } \\
\text { tempos em } \\
\text { tempos }\end{array}$ & $\begin{array}{l}\text { Realizado de } \\
\text { tempos em } \\
\text { tempos }\end{array}$ \\
\hline $\begin{array}{l}\text { v7 } \\
\text { compatibilidade } \\
\text { do material com } \\
\text { a politica da } \\
\text { qualidade }\end{array}$ & $\begin{array}{l}\text { regularmente } \\
\text { compativel }\end{array}$ & $\begin{array}{l}\text { pouco } \\
\text { compativel }\end{array}$ & $\begin{array}{l}\text { regularmente } \\
\text { compativel }\end{array}$ & $\begin{array}{l}\text { regularmente } \\
\text { compativel }\end{array}$ & $\begin{array}{l}\text { regularmente } \\
\text { compativel }\end{array}$ \\
\hline $\begin{array}{l}\text { v8 } \\
\text { definição das } \\
\text { funções, } \\
\text { relações } \\
\text { hierárquicas e } \\
\text { dos circuitos de } \\
\text { comunicação }\end{array}$ & nunca definidos & $\begin{array}{l}\text { muito pouco } \\
\text { definidos }\end{array}$ & $\begin{array}{l}\text { definidos em } \\
\text { grandes linhas }\end{array}$ & $\begin{array}{l}\text { definidos em } \\
\text { grandes linhas }\end{array}$ & bem definidos \\
\hline $\begin{array}{l}\text { v10 } \\
\text { verificação do } \\
\text { Manual da } \\
\text { Qualidade }\end{array}$ & jamais verificado & jamais verificado & jamais verificado & jamais verificado & $\begin{array}{l}\text { verificado de } \\
\text { maneira quase } \\
\text { regular }\end{array}$ \\
\hline $\begin{array}{l}\text { v12 } \\
\text { verificação dos } \\
\text { documentos } \\
\text { relacionados } \\
\text { com a qualidade }\end{array}$ & $\begin{array}{l}\text { jamais } \\
\text { verificados }\end{array}$ & $\begin{array}{l}\text { jamais } \\
\text { verificados }\end{array}$ & $\begin{array}{l}\text { poucas vezes } \\
\text { verificados }\end{array}$ & $\begin{array}{l}\text { verificados de } \\
\text { tempos em } \\
\text { tempos }\end{array}$ & $\begin{array}{l}\text { verificados de } \\
\text { maneira quase } \\
\text { regular }\end{array}$ \\
\hline
\end{tabular}

Tabela I- Perfil dos grupos de sistemas da qualidade com relação às varáveis discriminantes 
PRODUÇÃO =

No outro extremo, observa-se o grupo de empresas onde o sistema da qualidade é inexistente.

Com relação à avaliação dos sistemas da qualidade, os grupos podem ser identificados por suas características principais:

- Grupo 1: apesar do sistema da qualidade ser completamente inexistente, o pessoal da empresa está regularmente preocupado com a qualidade;

- Grupo 2: as empresas deste grupo descobrem a qualidade, se preocupam um pouco com ela, e até fixam objetivos sem os verificar;

- Grupo 3: este grupo de empresas caracteriza-se por estar iniciando todos os aspectos relacionados com a qualidade;

- Grupo 4: as empresas deste grupo tem seus sistemas da qualidade um pouco organizados, mas não se preocupam com os documentos relacionados com a qualidade;

- Grupo 5: neste grupo de empresas, os sistemas da qualidade estão melhor estruturados e organizados, existindo uma real preocupação com a qualidade.

Verificou-se que as empresas consultadas apresentaram três maneiras básicas e distintas de organizar os seus Sistemas da Qualidade:
- Grupo 5: apresenta um equilíbrio entre todos os elementos do sistema;

-Grupos 3 e 4: preocupam - se prioritariamente com alguns elementos do fator-chave 'recursos humanos e materiais' em detrimento do fator-chave 'responsabilidade da Administração';

- Grupos 1 e 2: organizam pouco os elementos do fator-chave responsabilidade da Administração' e não organizam os elementos do fator-chave 'estrutura do siste$m a '$.

Observou-se que de maneira geral, as empresas dos cinco grupos organizam de maneira semelhante os elementos do fatorchave 'recursos humanos e materiais', ou seja, priorizam a compatibilidade do material com a política da qualidade, em detrimento de programas de formação do pessoal à qualidade.

Serão apresentados a seguir, alguns dos resultados obtidos com a aplicação do questionário.

\begin{tabular}{|l|c|c|c|c|c|c|}
\hline \multirow{2}{*}{$\begin{array}{c}\text { Número de } \\
\text { Empregados }\end{array}$} & \multicolumn{4}{|c|}{ Tipos de Sistema da Qualidade } & Total de \\
\cline { 2 - 7 } empresas
\end{tabular}

Tabela II - Número de empregados em cada grupo de sistemas da qualidade 
4.1 . Número de empregados

Na tabela II, são apresentados os números de empregados correspondentes a cada grupo de empresas. Pode-se observar pelos dados apresentados nesta tabela que no grupo 1 , aproximadamente $70 \%$ das empresas deste grupo tem mais de 50 empregados. Isto pode indicar que a falta de organização com relação à qualidade não é exclusiva às pequenas empresas.

\section{2 . Formalismo dos sistemas da qualidade}

Outro resultado obtido neste estudo é a caracterização do formalismo dos sistemas da qualidade dos cinco grupos. Foram coletados os dados referentes às variáveis v14, v15, v16, v17, v18 e v19, apresentadas anteriormente. As questões relacionadas a estas variáveis avaliaram a existência formal dos elementos que as compõem. Estes dados foram analisados em relação às empresas de cada tipo de sistema da qualidade.

Na tabela III, são apresentados os dados das empresas dos cinco grupos, relacionados com as variáveis que avaliam o formalismo dos sistemas da qualidade. São apresentados os valores percentuais de empresas que apresentam estes elementos formalizados em cada grupo.

Pode-se observar nesta tabela, que a política da qualidade (v14) é definida formalmente somente em $25 \%$ das empresas pesquisadas. Nos grupos 4 e 5 , este elemento é formalizado em mais de $50 \%$ das empresas que compõem os referidos grupos. Com relação à verificação da política da qualidade (v15), pode-se observar que somente nos grupos 4 e 5 existe a verificação formal da política em aproximadamente $45 \%$ das empresas de cada grupo, sendo que na população, este número é de somente $16,7 \%$ das empresas.
Foi realizada uma análise estatística entre as empresas pertencentes a cada grupo de sistemas da qualidade e o grau de formalismo dos elementos avaliados. Foi aplicado o teste de hipótese do Qui-Quadrado em quatro das seis análises para verificar se há correlação, assim como o teste de um coeficiente de contingência para verificar a força desta correlação. Nas análises com as variáveis v14 (definição da política da qualidade) e v15 (verificação da política da qualidade), não foi possível aplicar o referido teste, pois as características encontradas durante sua aplicação o invalidaram. Para as variáveis v16 (definição dos objetivos da qualidade), v17 (verificação da realização dos objetivos da qualidade) e v19 (definição das funções, das relações hierárquicas e dos circuitos de comunicação), os testes indicam que a correlação encontrada entre o fato de pertencer a um grupo de sistema da qualidade e o de formalizar os elementos destas variáveis é moderadamente forte. Para a variável v18 (definição de programas para a formação do pessoal à qualidade), a correlação encontrada na análise entre pertencer a um grupo de sistema da qualidade e a formalização nesta variável é média.

O teste do Qui-Quadrado fez aparecer uma remarcável correlação entre o fato de adotar um tipo de sistema da qualidade e o grau de formalismo dos documentos relacionados com a qualidade. Para as empresas que adotam sistemas da qualidade como os dos grupos 5 e 4 , foi encontrado um formalismo maior de todos os seis elementos avaliados. Também foi visto que as empresas que pertencem aos grupos 1 e 2 possuem um grau de formalismo muito menor, exceto para a v18 (definição dos programas para a formação do pessoal à qualidade), que estava formalizado em $43,8 \%$ das empresas do grupo 1 , apesar das empresas neste grupo se preocuparem pouco com este componente do fator-chave 'recursos humanos e materiais'. 


\begin{tabular}{|l|c|c|c|c|c|c|}
\hline \multirow{2}{*}{$\begin{array}{c}\text { Grau de Formalismo } \\
\text { dos Sistemas }\end{array}$} & $\begin{array}{c}\text { Total na } \\
\text { população } \\
\text { (96) }\end{array}$ & $\begin{array}{c}\text { Grupo 1 } \\
\text { (16) }\end{array}$ & $\begin{array}{c}\text { Grupo 2 } \\
\text { (14) }\end{array}$ & $\begin{array}{c}\text { Grupo 3 } \\
\text { (26) }\end{array}$ & $\begin{array}{c}\text { Grupo 4 } \\
\text { (18) }\end{array}$ & $\begin{array}{c}\text { Grupo 5 } \\
\text { (17) }\end{array}$ \\
\hline $\begin{array}{l}\text { v14 - definição da politica } \\
\text { da qualidade }\end{array}$ & $25 \%$ & $12,5 \%$ & $14,3 \%$ & -- & $55,6 \%$ & $52,9 \%$ \\
\hline $\begin{array}{l}\text { v15 - verificação da } \\
\text { politica da qualidade }\end{array}$ & $16,7 \%$ & -- & -- & -- & $44,4 \%$ & $47,1 \%$ \\
\hline $\begin{array}{l}\text { v16 - definição dos } \\
\text { objetivos qualidade }\end{array}$ & $28,1 \%$ & $18,8 \%$ & $21,4 \%$ & -- & $61,1 \%$ & $52,9 \%$ \\
\hline $\begin{array}{l}\text { v17- verificação da } \\
\text { realização dos objetivos } \\
\text { da qualidade }\end{array}$ & $26 \%$ & $6,3 \%$ & $21,4 \%$ & $3,8 \%$ & $61,1 \%$ & $52,9 \%$ \\
\hline $\begin{array}{l}\text { v18 - definição de } \\
\text { programas para a } \\
\text { formação do pessoal à } \\
\text { qualidade }\end{array}$ & $28,1 \%$ & $43,8 \%$ & $7,1 \%$ & $11,5 \%$ & $33,3 \%$ & $52,9 \%$ \\
\hline $\begin{array}{l}\text { v19 - definição das } \\
\text { funções, das relações } \\
\text { hierárquicas e dos } \\
\text { circuitos de comunicação }\end{array}$ & $28,1 \%$ & $6,3 \%$ & $7,1 \%$ & $23,1 \%$ & $44,4 \%$ & $64,7 \%$ \\
\hline
\end{tabular}

Tabela III - Grau de formalismo dos sistemas da qualidade

A surpresa ficou com as empresas do grupo 3 , pois o grau de formalismo encontrado dos elementos e documentos do sistema da qualidade foi muito baixo, menor até que o encontrado nas empresas dos grupos 2 e 1, com exceção da variável v19 (definição das funções, das relações hierárquicas e dos circuitos de comunicação).

\subsection{Resultados obtidos com a certificação} ISO 9002

Para analisar os resultados obtidos pelas empresas classificadas segundo o tipo de sistema da qualidade existente antes da certificação ISO 9002, foram avaliadas doze variáveis relacionadas a três tipos diferentes de resultados:

- aumento dos lucros,

- melhorias no relacionamento com os clientes,

· melhorias na organização interna.
Para analisar o resultado 'aumento dos

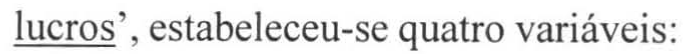

·v23 - evolução das vendas;

-v24 - notoriedade da empresa;

·v26 - crescimento da empresa com relação ao seu setor;

-v29 - produtividade da empresa.

Na tabela IV a seguir, são apresentados os dados das empresas dos cinco grupos de sistemas da qualidade, relacionados com as variáveis que avaliam o resultado sobre o aumento dos lucros. É importante ressaltar dois aspectos: o primeiro é referente à mudanças negativas com relação à estas quatro variáveis. Todas as empresas consultadas responderam que a certificação resultou em mudanças positivas ou em nenhuma mudança.

Outro aspecto a ser considerado, é que os resultados apresentados nesta tabela estão relacionados somente às empresas que responderam formalmente às questões, pois algumas consideraram que este tipo de informação é confidencial. 
Assim, em alguns casos, ocorre que a soma das respostas não constitui $100 \%$ das empresas de cada tipo de sistema da qualidade.
Para analisar o resultado 'melhorias no relacionamento com os clientes', estabeleceu-se quatro variáveis:

\begin{tabular}{|c|c|c|c|c|}
\hline \multirow{2}{*}{\multicolumn{2}{|c|}{ Aumento dos lucros }} & \multicolumn{3}{|c|}{ Tipo de Mudança } \\
\hline & & \multirow{2}{*}{$\begin{array}{c}\text { nenhuma } \\
\text { mudança } \\
50 \% \\
13 \% \\
19 \% \\
19 \%\end{array}$} & \multirow{2}{*}{$\begin{array}{c}\begin{array}{c}\text { fracas mudanças } \\
\text { positivas }\end{array} \\
19 \% \\
44 \% \\
31 \% \\
31 \%\end{array}$} & \multirow{2}{*}{$\begin{array}{c}\begin{array}{c}\text { mudanças muito } \\
\text { positivas }\end{array} \\
13 \% \\
38 \% \\
13 \% \\
31 \%\end{array}$} \\
\hline $\begin{array}{l}\text { Grupo } 1 \\
\text { (16 empresas) }\end{array}$ & $\begin{array}{l}\text { v23 } \\
\text { v24 } \\
\text { v26 } \\
\text { v29 } \\
\end{array}$ & & & \\
\hline $\begin{array}{l}\text { Grupo } 2 \\
\text { (14 empresas) }\end{array}$ & $\begin{array}{l}\text { v23 } \\
\text { v24 } \\
\text { v26 } \\
\text { v29 } \\
\end{array}$ & $\begin{array}{c}57 \% \\
7 \% \\
57 \% \\
14 \% \\
\end{array}$ & $\begin{array}{l}21 \% \\
21 \% \\
29 \% \\
50 \% \\
\end{array}$ & $\begin{array}{l}14 \% \\
71 \% \\
14 \% \\
36 \% \\
\end{array}$ \\
\hline $\begin{array}{l}\text { Grupo } 3 \\
\text { (26 empresas) }\end{array}$ & $\begin{array}{l}\text { v23 } \\
\text { v24 } \\
\text { v26 } \\
\text { v29 } \\
\end{array}$ & $\begin{array}{l}58 \% \\
23 \% \\
54 \% \\
35 \% \\
\end{array}$ & $\begin{array}{l}15 \% \\
35 \% \\
19 \% \\
54 \% \\
\end{array}$ & $\begin{array}{c}19 \% \\
42 \% \\
15 \% \\
8 \% \\
\end{array}$ \\
\hline $\begin{array}{l}\text { Grupo } 4 \\
\text { (18 empresas) }\end{array}$ & $\begin{array}{l}\text { v23 } \\
\text { v24 } \\
\text { v26 } \\
\text { v29 } \\
\end{array}$ & $\begin{array}{l}67 \% \\
44 \% \\
61 \% \\
28 \% \\
\end{array}$ & $\begin{array}{c}6 \% \\
28 \% \\
6 \% \\
44 \% \\
\end{array}$ & $\begin{array}{l}17 \% \\
22 \% \\
17 \% \\
28 \% \\
\end{array}$ \\
\hline $\begin{array}{l}\text { Grupo } 5 \\
\text { (17 empresas) }\end{array}$ & $\begin{array}{l}\text { v23 } \\
\text { v24 } \\
\text { v26 } \\
\text { v29 }\end{array}$ & $\begin{array}{l}29 \% \\
18 \% \\
24 \% \\
29 \% \\
\end{array}$ & $\begin{array}{l}35 \% \\
29 \% \\
29 \% \\
41 \% \\
\end{array}$ & $\begin{array}{l}24 \% \\
53 \% \\
24 \% \\
18 \%\end{array}$ \\
\hline
\end{tabular}

Tabela IV - Resultados dos grupos de sistemas da qualidade com relação ao aumento dos lucros

Com relação à evolução das vendas (v23), os tipos de sistemas da qualidade que apresentam os melhores resultados são: grupo 5 e grupo 3 . Com relação à notoriedade da empresa (v24), é possível observar que os tipos de empresas que apresentam as melhores melhorias são os grupos 2, 5 e o grupo 1 .

Também observa-se que as empresas do grupo 5 e do grupo 1 são aquelas que apresentam os melhores progressos com relação ao crescimento da empresa com relação ao seu setor (v26). Quanto à produtividade da empresa (v29), é possível observar que os tipos de empresa que apresentam maiores ganhos são aquelas do grupo 2 e do grupo 4. -v21 - rigor das auditorias dos clientes;

·v22 - atraso médio com relação aos prazos dos clientes;

·v25 - número médio de reclamações dos clientes;

-v28 - confiança dos clientes.

$\mathrm{Na}$ tabela $\mathrm{V}$ a seguir, são apresentados os resultados obtidos pelas empresas dos cinco grupos de sistemas da qualidade com relação à melhoria no relacionamento com os clientes. Novamente é importante salientar que os resultados apresentados nesta tabela relacionam-se somente às empresas que responderam formalmente às questões, pois algumas consideraram 
PRODUÇÃO

algumas destas informações são confidenciais. Assim, em alguns casos, ocorre que a soma das respostas não constitui $100 \%$ das empresas de cada tipo de sistema da qualidade.
Para analisar o resultado 'melhorias na organização interna', foram estabelecidas quatro variáveis:

\begin{tabular}{|l|l|c|c|c|}
\hline \multirow{2}{*}{$\begin{array}{c}\text { Melhorias no } \\
\text { relacionamento }\end{array}$} & \multicolumn{3}{|c|}{ Tipo de Mudança } \\
\cline { 2 - 5 } com os clientes & Mudança & $\begin{array}{c}\text { Fracas mudanças } \\
\text { positivas }\end{array}$ & $\begin{array}{c}\text { mudanças muito } \\
\text { positivas }\end{array}$ \\
\hline \multirow{2}{*}{ Grupo 1 } & v21 & $6 \%$ & $25 \%$ & $13 \%$ \\
(16 empresas) & v22 & $56 \%$ & $31 \%$ & $6 \%$ \\
& v25 & $25 \%$ & $25 \%$ & $50 \%$ \\
\hline \multirow{2}{*}{ Grupo 2 } & v28 & $6 \%$ & $38 \%$ & $54 \%$ \\
(14 empresas) & v21 & $14 \%$ & $7 \%$ & $36 \%$ \\
& v22 & $21 \%$ & $29 \%$ & $43 \%$ \\
G25 & $21 \%$ & $21 \%$ & $50 \%$ \\
Grupo 3 & v28 & $14 \%$ & $36 \%$ & $50 \%$ \\
& v21 & $8 \%$ & 0 & $12 \%$ \\
\hline \multirow{2}{*}{ Grupo 4 } & v22 & $46 \%$ & $35 \%$ & $54 \%$ \\
(18 empresas) & v25 & $31 \%$ & $35 \%$ & $17 \%$ \\
& v28 & $15 \%$ & $22 \%$ & $11 \%$ \\
\hline \multirow{2}{*}{ Grupo 5 } & v22 & $33 \%$ & $6 \%$ & $28 \%$ \\
(17 empresas) & v25 & $61 \%$ & $28 \%$ & $59 \%$ \\
& v28 & $17 \%$ & $64 \%$ & $24 \%$ \\
\hline
\end{tabular}

Tabela $\mathrm{V}$ - Resultados das empresas com relação à melhorias no relacionamento com os clientes

Com relação ao rigor das auditorias dos clientes (v21), é possível observar que os sistemas da qualidade das empresas do grupo 5 e do grupo 2 , são aqueles que obtiveram as melhores melhorias. Quanto ao atraso médio com relação aos prazos dos clientes (v22), os grupos que apresentam melhores resultados são os grupos 2 e 5.

Quanto ao número médio de reclamações dos clientes (v25), as empresas dos grupos 1 e 2 , são as que apresentam melhores progressos. Com relação à confiança dos clientes, observa-se que as empresas do grupo 5, do grupo 2 e do grupo 3 são as mais beneficiadas pela certificação. ·v22 - atraso médio com relação aos prazos dos clientes;

·v27 - comunicação interna;

•v29 - produtividade da empresa;

·v30 - motivação do pessoal;

vv31 - organização interna;

·v32 - custos resultantes da não-qualidade.

Na tabela VI a seguir, são apresentados os resultados obtidos pelas empresas dos cinco grupos de sistemas da qualidade com relação à melhorias na organização interna. É importante ressaltar mais uma vez que, os resultados apre- 
sentados nesta tabela consideram somente as empresas que responderam formalmente à estas questões, pois algumas consideraram que algumas destas informações constituem-se de dados confidenciais. Portanto, em alguns casos, pode ocorrer que a soma das respostas não constitui $100 \%$ das empresas de cada tipo de sistema da qualidade. melhores resultados. Isto pode ser explicado pelo fato das empresas dos outros grupos possuírem sistemas da qualidade melhor organizados antes de iniciarem seus processos de certificação.

Com relação à produtividade da empresa (v29), os maiores ganhos são observados nas empresas dos grupos 2 e 4. Quanto à motivação

\begin{tabular}{|c|c|c|c|c|}
\hline \multirow{2}{*}{\multicolumn{2}{|c|}{\begin{tabular}{|c|} 
Melhorias na \\
organização interna
\end{tabular}}} & \multicolumn{3}{|c|}{ Tipo de Mudança } \\
\hline & & $\begin{array}{l}\text { nenhuma } \\
\text { mudanca }\end{array}$ & $\begin{array}{c}\text { fracas mudanças } \\
\text { positivas }\end{array}$ & $\begin{array}{c}\text { mudanças muito } \\
\text { positivas }\end{array}$ \\
\hline $\begin{array}{l}\text { grupo } 1 \\
\text { (16) }\end{array}$ & $\begin{array}{l}\text { v22 } \\
\text { v27 } \\
\text { v29 } \\
\text { v30 } \\
\text { v31 } \\
\text { v32 }\end{array}$ & $\begin{array}{c}56 \% \\
6 \% \\
19 \% \\
19 \% \\
-- \\
19 \%\end{array}$ & $\begin{array}{l}31 \% \\
50 \% \\
31 \% \\
50 \% \\
38 \% \\
25 \%\end{array}$ & $\begin{array}{c}6 \% \\
44 \% \\
31 \% \\
31 \% \\
56 \% \\
25 \%\end{array}$ \\
\hline $\begin{array}{l}\text { grupo } 2 \\
\text { (14) }\end{array}$ & $\begin{array}{l}\text { v22 } \\
\text { v27 } \\
\text { v29 } \\
\text { v30 } \\
\text { v31 } \\
\text { v32 }\end{array}$ & $\begin{array}{c}21 \% \\
7 \% \\
14 \% \\
-- \\
-- \\
14 \%\end{array}$ & $\begin{array}{l}29 \% \\
29 \% \\
50 \% \\
43 \% \\
21 \% \\
57 \%\end{array}$ & $\begin{array}{l}36 \% \\
64 \% \\
36 \% \\
57 \% \\
79 \% \\
21 \%\end{array}$ \\
\hline $\begin{array}{l}\text { grupo } 3 \\
\text { (26) }\end{array}$ & $\begin{array}{l}\text { v22 } \\
\text { v27 } \\
\text { v29 } \\
\text { v30 } \\
\text { v31 } \\
\text { v32 }\end{array}$ & $\begin{array}{l}6 \% \% \\
15 \% \\
35 \% \\
23 \% \\
12 \% \\
27 \%\end{array}$ & $\begin{array}{l}35 \% \\
46 \% \\
54 \% \\
58 \% \\
23 \% \\
27 \%\end{array}$ & $\begin{array}{c}12 \% \\
38 \% \\
8 \% \\
15 \% \\
65 \% \\
27 \%\end{array}$ \\
\hline $\begin{array}{l}\text { Grupo } 4 \\
\text { (18) }\end{array}$ & $\begin{array}{l}\text { v22 } \\
\text { v27 } \\
\text { v29 } \\
\text { v30 } \\
\text { v31 } \\
\text { v32 }\end{array}$ & $\begin{array}{c}61 \% \\
11 \% \\
28 \% \\
11 \% \\
-- \\
17 \%\end{array}$ & $\begin{array}{c}6 \% \\
33 \% \\
44 \% \\
44 \% \\
28 \% \\
39 \%\end{array}$ & $\begin{array}{l}11 \% \\
56 \% \\
28 \% \\
44 \% \\
67 \% \\
22 \%\end{array}$ \\
\hline $\begin{array}{l}\text { Grupo } 5 \\
\text { (17) }\end{array}$ & $\begin{array}{l}\text { v22 } \\
\text { v27 } \\
\text { v29 } \\
\text { v30 } \\
\text { v31 } \\
\text { v32 }\end{array}$ & $\begin{array}{l}35 \% \\
12 \% \\
29 \% \\
24 \% \\
12 \% \\
18 \%\end{array}$ & $\begin{array}{l}35 \% \\
24 \% \\
41 \% \\
35 \% \\
35 \% \\
41 \%\end{array}$ & $\begin{array}{l}24 \% \\
65 \% \\
18 \% \\
35 \% \\
53 \% \\
35 \%\end{array}$ \\
\hline
\end{tabular}

Tabela VI - Resultados dos grupos de sistemas da qualidade com relação à melhorias na organização interna

Quanto ao atraso médio com relação aos prazos dos clientes (v22), as empresas que apresentam as melhores melhorias são aquelas dos grupos 2 e 5 . No que se refere à comunicação interna (v27), os grupos 2 e 1 obtiveram os do pessoal (v30), observa-se que as empresas que obtiveram os melhores resultados são aquelas dos grupos 2 e 4 .

No que se refere à organização interna (v31), as empresas dos grupos 2, 4 e 1 são 
PRODUÇÃO

as empresas onde pode-se observar os melhores progressos. Quanto aos custos resultantes da não-qualidade (v32), é possível observar na tabela acima que as empresas dos grupos 2 e 5 apresentam os melhores ganhos.

Globalmente, esta análise pode levar à algumas conclusões. Com relação ao resultado 'aumento dos lucros', as empresas que possuíam um sistema da qualidade como no grupo 5 (sistemas bem estruturados) e do grupo 2 (sistemas muito pouco estruturados) são aquelas onde a certificação ISO 9002 trouxe mais mudanças positivas. Esta situação se repete para o resultado 'melhorias no relacionamento com os clientes'.

Com relação ao resultado 'melhorias na organização interna', os grupos de empresas onde houve maiores ganhos com a certificação, foram os grupos 2 (sistemas muito pouco estruturados) e 4 (sistemas um pouco melhor organizados).

Assim, é possível concluir que a certificação proporcionou maiores benefícios de origem externa (aumento dos lucros e melhorias no relacionamento com os clientes), não somente às empresas que já possuíam um sistema da qualidade bem estruturado, como é o caso das empresas do grupo 5, como também àquelas empresas onde a organização dos sistemas da qualidade era mínima, como no grupo 2 .

Com relação aos benefícios de ordem interna (melhorias na organização interna), as empresas que obtiveram melhores resultados com a certificação ISO 9002 são aquelas onde os sistemas da qualidade estavam pouco estruturados, como é o caso das empresas do grupo 2 e também para as empresas onde os sistemas da qualidade estavam um pouco melhor estruturados, como as do grupo 4 .

\section{Conclusões}

Os resultados encontrados neste estudo permitiram a validação do modelo proposto e a caracterização das empresas segundo a estruturação de seus Sistemas da Qualidade. Pode-se observar que o modelo proposto neste trabalho para análise do sistema da qualidade segundo os três fatores-chaves que o compõem, possibilitou o diagnóstico dos pontos fortes e fracos dos mesmos nas empresas consultadas. Estas tem assim, uma ferramenta que pode auxiliar na correção das disfunções e na melhoria contínua de todos os elementos que compõem seus Sistemas da Qualidade.

Na pesquisa realizada, foi possível identificar uma tipologia de 5 grupos de empresas, segundo a maneira de organizar seus sistemas da qualidade com relação às treze variáveis que avaliam os três fatores-chaves dos sistemas da qualidade: a responsabilidade da Administração, os recursos humanos e materiais e a estrutura do próprio sistema.

Foram encontradas nesta pesquisa cinco diferentes maneiras de organizar os sistemas da qualidade: no Grupo 1, apesar do sistema da qualidade ser completamente inexistente, o pessoal da empresa está regularmente preocupado com a qualidade; as empresas do Grupo 2 descobrem a qualidade, preocupam-se um pouco com ela, e até fixam objetivos sem os verificar; o Grupo 3 de empresas caracteriza-se por estar iniciando todos os aspectos relacionados com a qualidade. As empresas do Grupo 4 têm seus sistemas da qualidade um pouco organizados, mas não se preocupam com os documentos relacionados com a qualidade; e no Grupo 5, os sistemas da qualidade estão melhor estruturados e organizados, existindo uma real preocupação das empresas deste grupo com a qualidade. 
Foram observados nesta pesquisa os resultados que as empresas consultadas obtiveram após a obtenção do certificado ISO 9002. Pode-se observar que, globalmente, as empresas dos grupos onde havia um sistema da qualidade bem estruturado, como no Grupo 5 são aquelas que mais obtiveram resultados de origem externa (aumento dos lucros e melhorias no relacionamento com os clientes) com a referida certificação. Com relação aos resultados internos obtidos com a certificação ISO 9002 (melhorias na organização interna), as empresas onde os sistemas da qualidade estavam pouco estruturados, como é o caso do Grupo 2, foram as que apresentaram melhores resultados.

O modelo para o diagnóstico dos sistemas da qualidade se mostra muito útil para o diagnóstico dos sistemas da qualidade nas empresas que desejam iniciar seus projetos de certificação à uma das normas ISO 9000, pois o modelo considera aspectos fundamentais dos sistemas da garantia da qualidade e possibilita às empresas visualizar o percurso por onde deve começar a estruturação deste tipo de sistema.

Também é possível aplicar o modelo proposto às empresas que querem iniciar um programa da qualidade total, pois, além de possibilitar a visualização dos pontos fortes e fracos da organização já existentes nas empresas com relação à qualidade, as empresas têm assim um indicador dos elementos que devem ser melhorados ou reestruturados.
6. Referências Bibliográficas

PRODUÇÃO

DEFOURNEY V. \& NOYÉ D., Du bon usage des mots de la qualidade - Les principaux termes: definitions e commentaires, INSEP Editions, Paris, 1996.

DE MEDEIROS, D. D., Le projet de certification ISO 9002 : aide au choix et caractérisation des différentes démarches, Thèse de Doctorat, Institut National Polytechnique de Grenoble, Spécialité Génie Industriel - France, Septembre 1998.

DEMING W. E., Qualidade: A revolução da Administração, Marques Saraiva, Rio de Janeiro, 1990.

JURAN J. M., Juran na Liderança pela Qualidade - Um guia para executivos, Pioneira, São Paulo, 1993.

NORMA ISO 9001:1994, Sistemas da qualidade: modelo para garantia da qualidade em projeto, desenvolvimento, produção, instalação e serviços associados. International Standards Organization, Geneva, 1994.

NORMA ISO 9002:1994, Sistemas da qualidade: modelo para garantia da qualidade em produção e instalação. International Standards Organization, Geneva, 1994.

NORMA ISO 9004-1:1994, Normas de gestão da qualidade e elementos do sistema da qualidade - Parte 1: Diretrizes, International Standards Organization, Geneva, 1994.

NORMA ISO 9004-2:1994, Gestão da qualidade e elementos do sistema da qualidade Parte 2: Linhas diretrizes para os serviços, International Standards Organization, Geneva, 1994.

RICHARDSON, R. J. Pesquisa social: métodos e técnicas, Atlas, São Paulo, 1985. 